\title{
In vitro analysis of femtosecond laser as an alternative to acid etching for achieving suitable bond strength of brackets to human enamel
}

\author{
M. C. Lorenzo • M. Portillo • P. Moreno • J. Montero • \\ R. Castillo-Oyagüe • A. García • A. Albaladejo
}

Received: 20 November 2012 / Accepted: 28 January 2013 / Published online: 13 March 2013

(C) Springer-Verlag London 2013

\begin{abstract}
This study aims to evaluate the effect of laser irradiation and orthophosphoric acid etching on the shear bond strength (SBS) of orthodontic brackets to enamel. Three groups $(n=20)$ of extracted premolar teeth were randomly established depending on the laser treatment performed on the buccal surfaces: (1) no laser (control); (2) Er:YAG laser $(2,940 \mathrm{~nm}, 0.8 \mathrm{~W}, 100 \mu \mathrm{s} /$ pulse, $10 \mathrm{~Hz})$ and; (3) Ti:Sapphire laser (795 nm, $1 \mathrm{~W}, 120 \mathrm{fs} /$ pulse, $1 \mathrm{kHz})$. Each group was divided into two subgroups according to whether $37 \%$-orthophosphoric acid etching was made after laser irradiation or not. Brackets were randomly luted with Transbond $^{\mathrm{TM}}$ XT adhesive resin. After $72 \mathrm{~h}$, a SBS test was developed in a universal testing machine (crosshead speed, $0.5 \mathrm{~mm} / \mathrm{min}$ ). Representative specimens from each experimental subgroup were examined by means of scanning electron microscopy. Cement residuals remaining on the premolar surfaces were assessed using the adhesive remnant
\end{abstract}

M. C. Lorenzo $(\varangle) \cdot$ M. Portillo $\cdot$ J. Montero $\cdot$ A. Albaladejo Dental Clinic (Faculty of Medicine), University of Salamanca, Paseo Universidad de Coimbra, s/n, 37007 Salamanca, Spain e-mail: mcruzlorenzo@hotmail.com

P. Moreno · A. García

Laser Microprocessing Research Group,

University of Salamanca, Plaza de la Merced,

s/n, 37008 Salamanca, Spain

R. Castillo-Oyagüe

Department of Buccofacial Prostheses,

Faculty of Dentistry, Complutense University

of Madrid (U.C.M.), Pza. Ramón y Cajal,

s/n, 28040 Madrid, Spain index. ANOVA, post-hoc tests for intergroup comparisons, chi-square test and linear regression were run for data analyses $(\alpha=0.05)$. After acid etching, SBS values did not differ regardless the laser treatment. When phosphoric acid was not applied, the SBS values of the femtosecond laser group were significantly higher than for the other groups. Femtosecond laser without acid seems to be the most suitable method to improve bond strengths at the bracket/enamel interface, thus avoiding the disadvantages inherent to acid etching.

Keywords Femtosecond laser · Enamel · Adhesion . Shear bond strength

\section{Introduction}

The application of $37 \%$-phosphoric acid for $15 \mathrm{~s}$ remains the most common conditioning method for bonding brackets to enamel [1-3]. Despite demonstrating optimal bond strength values [4], the demineralization of the most superficial enamel layer is a potential drawback [5]. As a result, the surface becomes more sensitive to long-term acid attack and caries, mainly in case of incomplete or defective resin impregnation [2, 6].

Exposing enamel to laser irradiation seems to provide some degree of protection against demineralization under acid attack [7]. Laser devices have been used for soft tissue surgery, root end sealing and sterilization; and for altering enamel and dentin surfaces to increase resistance to decay or facilitate bonding of composite resins [8-12]. Nonetheless, whereas some studies report significantly lower bond 
strengths for laser-structured than for acid-etched teeth [2, 4, 13, 14]; others show comparable or even stronger bond strength values for laser treatment [15-17].

The Erbium lasers were specifically introduced in dentistry for cutting enamel and dentin [18, 19]. These lasers emit energy in the wavelength range of 2.6-3 $\mu \mathrm{m}$. Such interval coincides with the strongest absorption peak of water, which is an important component of dental hard tissues [20]. In particular, the Er:YAG laser $(2,940 \mathrm{~nm})$ radiation is strongly absorbed by water and hydroxyapatite.

During the last decade, ultrashort pulsed lasers have been tested as a potential and alternative tool for dental surgery and orthodontics. Sapphire crystals doped with titanium (Ti: $\mathrm{Sa}$ ) are the main source to produce laser pulses with a duration in the range of the tens and hundreds of femtoseconds. These laser pulses, amplified up to energies of the order of millijoule [21] and conveniently focused on the materials surface, allow the ablation of thin layers with outstanding precision and reproducibility, which may result in much less collateral damage to the adjacent elements than any other thermal, chemical or mechanical process [22, 23]. These lasers have already been used on dental hard tissues $[24,25]$. The absorption of ultrashort laser radiation is painless and does not involve vibration or heating. Such qualities make them good candidates for use in dental practice [26].

To our knowledge, there is no previous study comparing the performance of ultrashort lasers with regard to other conventional techniques for improving the bond strength of different orthodontic attachments to enamel surfaces.

Accordingly, the aim of the present in vitro study is to evaluate the influence of two different laser treatments (Er: YAG and ultrashort) and orthophosphoric acid etching on the shear bond strength (SBS) of orthodontic brackets to enamel. The null hypothesis tested is that neither laser treatment nor acid etching, nor the combination of both techniques, influences the SBS of brackets to human enamel.

\section{Materials and methods}

Sample preparation and storage

A schematic illustration of the preparation of specimens is shown in Fig. 1. Sixty extracted human premolar teeth were collected and stored in a 0.5 chloramine $\mathrm{T}$ solution for a maximum of six months after extraction. Exclusion criteria included previously restored premolars and premolars with enamel defects or cracking and delamination of the enamel.

Premolar teeth were examined with an Axio M1 light microscope (Carl Zeiss, Oberkochen, Germany) operating in the dark-field mode. Epiplan $\times 20$ and $\times 50$ HD objectives
(Carl Zeiss Vision) were attached to a $1300 \times 1030$-pixel digital camera (AxioCam HR, Carl Zeiss Vision). Consistent with the exclusion criteria, the selected premolar teeth were mounted in self-cured acrylic blocks. The buccal surfaces were oriented perpendicularly to the bottom of the molds so that the bonded interfaces were parallel to the force applied during the later SBS test.

Before laser irradiation and acid etching, the buccal crown surface of each premolar was polished for $15 \mathrm{~s}$ with fluoride-free pumice slurry, washed for $30 \mathrm{~s}$ and dried for $10 \mathrm{~s}$ with a moisture-free air spray.

\section{Experimental groups}

Prior to bonding the metal brackets, the premolar teeth were randomly assigned to three groups $(n=20)$ depending on the laser treatment to be applied on the enamel surfaces: (1) no laser (control); (2) Er:YAG laser (Fidelis Plus III; Fotona, Ljubljana, Slovenia), and (3) ultrashort pulsed laser (Tsunami; Spectra Physics, Mountain View, CA, USA).

\section{Laser irradiation}

\section{Erbium laser processing}

The Er:YAG laser used in the study emits at a wavelength $(\lambda)$ of $2,940 \mathrm{~nm}$. The irradiation was performed under the following conditions: $80 \mathrm{~mJ} / \mathrm{pulse}$, VSP $(100 \mu \mathrm{s}), 10 \mathrm{~Hz}$, output power of $0.8 \mathrm{~W}$, focal distance of $10 \mathrm{~mm}$ and beam spot diameter of $0.5 \mathrm{~mm}$ with a non-contact handpiece (R02). The enamel surfaces were previously moistened to avoid cracking and fusion and were cooled with water spray during irradiation. To simulate as closely as possible actual clinical performance, the laser beam was manually directed without the use of any fixed support.

\section{Ultrashort laser processing}

The laser system consists of a commercial Ti:Sapphire oscillator (Tsunami; Spectra Physics) which provides pulses in the near infrared $(\lambda=795 \mathrm{~nm})$ and a regenerative amplifier (Spitfire; Spectra Physics) based on the chirped pulse amplification technique [21] which allows to increase the pulse energy up to $1 \mathrm{~mJ}$. The system delivers pulses with a duration of approximately $120 \mathrm{fs}$, at a repetition rate of $1 \mathrm{kHz}$ and a maximum output power of $1 \mathrm{~W}$.

The pulse energy is finely controlled by a half-wave plate and a linear polarizer. Neutral density filters were used when further energy reduction was required. The average power of the beam was measured with a thermopile detector (407A; Spectra Physics). The transversal mode is nearly a Gaussian TEM00 with a $9 \mathrm{~mm}$ beam diameter (at 1/e2). The laser pulses were focused by means of achromatic doublet 
Fig. 1 Schematic model of the experiment

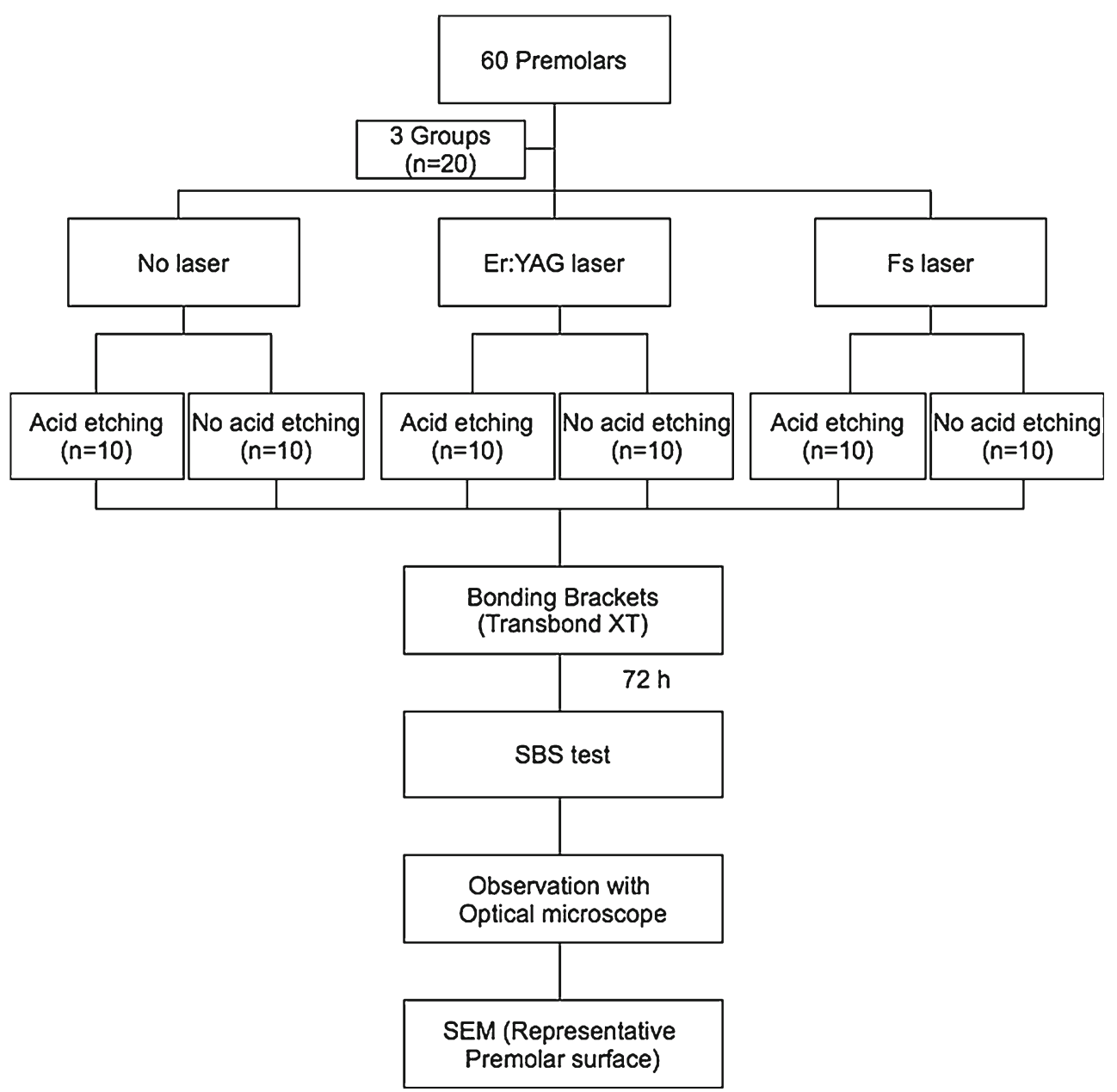

previous works on ultrashort laser processing of hard dental tissues $[23,25]$. The focal length of the lens, the pulse energy $(0.03 \mathrm{~mJ})$, the scanning velocity $(0.5 \mathrm{~mm} / \mathrm{s})$ and the pitch between adjacent scans $(0.015 \mathrm{~mm})$ were chosen to generate smoothly overlapping and swallow microstructures.

The teeth samples were laser processed in a saturated vapor atmosphere to preserve the dental tissues from drying. All of the tested specimens were stored in distilled water before and after laser irradiation.

\section{Acid etching}

For each experimental group, half of the specimens $(n=10)$ were acid-etched for $30 \mathrm{~s}$ by spreading $37 \%$ phosphoric acid gel (3M ${ }^{\mathrm{TM}}$ ESPE $^{\mathrm{TM}}$ Scotchbond ${ }^{\mathrm{TM}}$, 3M ESPE, St. Paul, MN, USA) on the enamel surface areas where the brackets were to be located (ROI). Afterwards, the buccal enamel surfaces were rinsed with tap water for $10 \mathrm{~s}$ and dried with oil-free and moisture-free air for $20 \mathrm{~s}$ until the enamel had a faintly white appearance as recommended by the manufacturers. 
Bonding procedure

Sixty brackets having micro-etched bases (3M Unitek, Monrovia, CA, USA) were randomly bonded to the premolars' buccal surfaces using a total etch adhesive system to enamel consisting of a combination of a primer and an orthodontic adhesive resin (Transbond ${ }^{\mathrm{TM}} \mathrm{XT}$; 3M-Unitek, St. Paul, MN, US). The manufacturer's composition and application mode of the materials used in the experiment are detailed in Table 1.

The adhesive resin was applied to each bracket base (area, $9.15 \mathrm{~mm}^{2}$ ) after priming both the tooth and the bracket surfaces [27]. Brackets were then positioned onto the buccal enamel surfaces and pressed firmly with a Hollenback carver to expel the excess adhesive. Each bracket was subjected to a 300 -g compressive force using a force gauge (Correx, Berne, Switzerland) for $10 \mathrm{~s}$, after which excess bonding resin was removed using a sharp scaler. Then, the composite was lightcured for $20 \mathrm{~s}$ from the occlusal and gingival bracket edges.

The bonding resin was photocured with a LED unit (Bluephase G2; Ivoclar-Vivadent, Schaän, Liechtenstein) emitting in the wavelength range $380-515 \mathrm{~nm}$ and a light intensity of $1,000 \mathrm{~mW} / \mathrm{cm}^{2}$ measured with a built-in radiometer (Bluephase Meter, Ivoclar-Vivadent) which was calibrated every $10 \mathrm{~min}$ to ensure consistent light intensity.

Shear bond strength test

The bracketed teeth were immersed in sealed containers of deionized water and placed in an incubator at $37^{\circ} \mathrm{C}$ for $72 \mathrm{~h}$ to permit adequate water absorption and equilibration. To conduct the SBS test, the specimens were secured in a jig attached to the base plate of a universal testing machine (Autograph AGS-X 10 KN, Shimadzu, Tokyo, Japan).
The teeth were set at the base of the machine so that the sharp end of the rod incised in the area between the base and the wings of the bracket, exerting a force parallel to the tooth surface in an occluso-apical direction (crosshead speed, $0.5 \mathrm{~mm} / \mathrm{min}$ ). The force required to debond each bracket was registered in newtons $(\mathrm{N})$ and converted into megapascals $(\mathrm{MPa})$ as a ratio of $\mathrm{N}$ to the bracket's surface area.

Failure mode analysis

After the SBS test, each specimen was examined under an optical microscope (Axio M1; Carl Zeiss) at $\times 50$ magnification to identify the location of the bond failure. The adhesive layers left on the premolar surfaces were assessed by using the adhesive remnant index (ARI), where each specimen was scored according to the amount of material remaining on the enamel surface as follows: $0=$ no adhesive remaining; $1=$ less than $50 \%$ of the adhesive remaining; $2=$ more than $50 \%$ of the adhesive remaining and $3=$ all adhesive remaining with a distinct impression of the bracket base.

\section{Scanning electron microscope analysis}

Representative premolar surfaces were prepared for scanning electron microscope (SEM) analysis. Samples were dehydrated for $48 \mathrm{~h}$ in a desiccator (Sample Dry Keeper Simulate Corp., Tokyo, Japan) and sputter coated with a 10$\mathrm{nm}$ platinum layer in a Polaron E5100 SEM coating unit (Polaron Equipment Ltd., Hertfordshire, England, UK). The morphology of the debonded enamel surfaces was then examined with a variable-pressure SEM (Zeiss EVO MA 25; Carl Zeiss, Jena, Germany).

Table 1 Manufacturer, main composition and application mode of the materials tested

\begin{tabular}{|c|c|c|c|}
\hline Material & Manufacturer & Main components & Mode/steps of application \\
\hline $\begin{array}{l}\text { Scotchbond }^{\mathrm{TM}} 37 \% \\
\text { phosphoric acid }\end{array}$ & $\begin{array}{l}\text { 3M ESPE, St. Paul, } \\
\text { MN, US }\end{array}$ & $37 \%$ phosphoric acid & $\begin{array}{l}\text { The area where the bracket was to be located was } \\
\text { etched with a } 37 \% \text { phosphoric acid gel for } 30 \mathrm{~s} \text {, } \\
\text { rinsed for } 15 \mathrm{~s} \text {, and dried with oil-free and moisture- } \\
\text { free air for } 20 \mathrm{~s} \text { until the enamel had a faintly white } \\
\text { appearance }\end{array}$ \\
\hline Transbond $^{\mathrm{TM}} \mathrm{XT}$ & $\begin{array}{l}\text { 3M Unitek; St. Paul, } \\
\text { MN, US }\end{array}$ & $\begin{array}{l}\text { Primer: Bis-GMA (Bisphenol } \\
\text { A-glycidyl methacrylate), } \\
\text { TEGDMA (triethylene glycol } \\
\text { dimethacrylate). Adhesive paste: } \\
\text { Silane-treated quartz, Bis-GMA, } \\
\text { dichlorodimethylsilane reaction } \\
\text { product with silica }\end{array}$ & $\begin{array}{l}\text { Primer: air-dry the tooth surfaces thoroughly. Place a } \\
\text { thin uniform layer of Transbond }{ }^{\mathrm{TM}} \text { XT primer on } \\
\text { the bracket base and on the tooth enamel surface to } \\
\text { be bonded. Adhesive: Apply a thin coat of } \\
\text { Transbond }{ }^{\mathrm{TM}} \text { XT orthodontic adhesive onto the base } \\
\text { of each bracket and seat it firmly in place. A } \\
\text { minimum amount of composite resin must be } \\
\text { utilized to avoid excessive adhesive flash. Scale the } \\
\text { excess resin from around the brackets. Photo-cure } \\
\text { for } 20 \mathrm{~s} \text { from the occlusal edge and } 20 \mathrm{~s} \text { from the } \\
\text { gingival bracket edge }\end{array}$ \\
\hline
\end{tabular}


Table 2 Mean and standard deviation (SD) of the shear bond strength (SBS) values (MPa) obtained in the experimental groups

\begin{tabular}{llll}
\hline Enamel surface treatments & No laser (control) & Er:YAG laser & Ti:Sapphire laser \\
\hline With acid etching & Mean: 18.6 b B & Mean: 20.2 b B & Mean: 22.0 b B \\
& SD: 5.0 & SD: 10.9 & SD: 7.9 \\
Without acid etching & Mean: 6.4 a A & Mean: 7.8 a A & Mean: 22.9 b B \\
& SD: 2.4 & SD: 7.0 & SD: 8.3 \\
\hline
\end{tabular}

ANOVA test: $F=9.698 ; P<0.001$

Similar lowercase letters in rows and equal capital letters in columns indicate the absence of significant differences

Specific areas of the brackets were also explored to identify possible differences among the experimental groups with respect to the surface topography of such brackets.

\section{Statistical analysis}

Descriptive statistics including means and standard deviations were calculated for the SBS values. Differences in SBS among the experimental groups were examined using ANOVA and Bonferroni multiple comparisons test.

To assess the influence of acid etching and laser surface treatment on SBS, a step-wise multiple linear regression was run, the SBS being the dependent variable. The predictive variable named "Laser" was divided into two dummy variables considering the absence of laser treatment as "control" reference (i.e., Laser 1=Er:YAG against control; Laser 2=ultrashort laser against control). The Determination Coefficient $\left(R^{2}\right)$ was taken as the indicator of the model fit.

The ARI scores were analyzed for percentage and frequency of fracture type, and a chi-square test was used to compare acid-etched and non acid-etched samples within each laser treatment group. The ARI scores were categorized as $A R I=0-1$ vs. $A R I=2-3$ for statistical comparisons.

All of the statistical analyses were performed using the SPSS v.18 software for Windows (Statistical Package for the Social Sciences, Chicago IL, USA). Significance for all statistical tests was predetermined at $P<0.05$. A $P$ value in the $0.05-0.10$ range was regarded as an indicator of a trend towards statistical significance.

\section{Results}

Shear bond strength

Concerning the non acid-etched samples, those treated with ultrashort laser showed statistically higher SBS than those treated with Er:YAG laser or no laser (control), which were statistically similar to each other (Table 2).

When applying acid etching, the three laser treatment groups performed equally concerning the SBS of brackets to human enamel (Table 2).

Acid etching caused no significant effect on SBS in combination with ultrashort laser, whereas within the control and Er:YAG laser groups, acid-etched samples recorded significantly higher SBS values (Table 2).

The Multiple Linear Regression model that attempted to predict the model stress values according to acid etching and laser type $(\mathrm{MPa})$ was significant $(\mathrm{Chi}$-square $=27.69 ; \mathrm{gl}=3$; $P<0.001)$. Acid etching significantly enhanced the SBS values $(7.87 \mathrm{MPa} ; P<0.001)$. Among the laser systems tested, the ultrashort laser was the only that significantly improved the adhesion as compared to the control group (9.93 MPa; $P<0.001)$. The Er:YAG laser tended to increase the SBS values at the adhesive interface, but not significantly (1.46 MPa; $P=0.55)$.

Table 3 Cross-tabulation of the effect of acid etching within the laser treatment groups according to a dichotomous variable generated from the ARI scores ( $0-1$ score vs. $2-3$ scores)

\begin{tabular}{|c|c|c|c|c|c|c|c|c|}
\hline \multirow[t]{3}{*}{ ARI } & \multicolumn{6}{|c|}{ Laser groups } & \multirow{2}{*}{\multicolumn{2}{|c|}{ Total: $n(\%)$}} \\
\hline & \multicolumn{2}{|c|}{ No laser: $n(\%)$} & \multicolumn{2}{|c|}{ Er:YAG laser: $n(\%)$} & \multicolumn{2}{|c|}{ Ti:Sapphire laser: $n(\%)$} & & \\
\hline & $\begin{array}{l}\text { With } \\
\text { etching }\end{array}$ & $\begin{array}{l}\text { Without } \\
\text { etching }\end{array}$ & $\begin{array}{l}\text { With } \\
\text { etching }\end{array}$ & $\begin{array}{l}\text { Without } \\
\text { etching }\end{array}$ & $\begin{array}{l}\text { With } \\
\text { etching }\end{array}$ & $\begin{array}{l}\text { Without } \\
\text { etching }\end{array}$ & $\begin{array}{l}\text { With } \\
\text { etching }\end{array}$ & $\begin{array}{l}\text { Without } \\
\text { etching }\end{array}$ \\
\hline 0 -1 scores & $3(30.0)$ & $10(100.0)$ & $8(80.0)$ & $9(90.0)$ & $2(20.0)$ & $7(70.0)$ & $13(43.3)$ & $26(86.7)$ \\
\hline 2-3 scores & $7(70.0)$ & $0(0.0)$ & $2(20.0)$ & $1(10.0)$ & $8(80.0)$ & $3(30.0)$ & $17(56.7)$ & $4(13.3)$ \\
\hline \multicolumn{3}{|c|}{$\begin{array}{l}\text { Chi-square }=10.77 \\
P<0.01\end{array}$} & \multicolumn{2}{|c|}{$\begin{array}{c}\text { Chi-square }=0.39 \\
P=0.53\end{array}$} & \multicolumn{2}{|c|}{$\begin{array}{l}\text { Chi-square }=5.05 \\
P<0.05\end{array}$} & \multicolumn{2}{|c|}{$\begin{array}{l}\text { Chi-square }=12.38 \\
\quad P<0.001\end{array}$} \\
\hline
\end{tabular}


Fig. 2 SEM micrographs $(1 \mathrm{kV})$ of a debonded sample treated with "no laser/no acid" $(\mathbf{a} \times 55 ; \mathbf{b} \times 2.06 \mathrm{~K})$. Enamel cracks are labeled in white
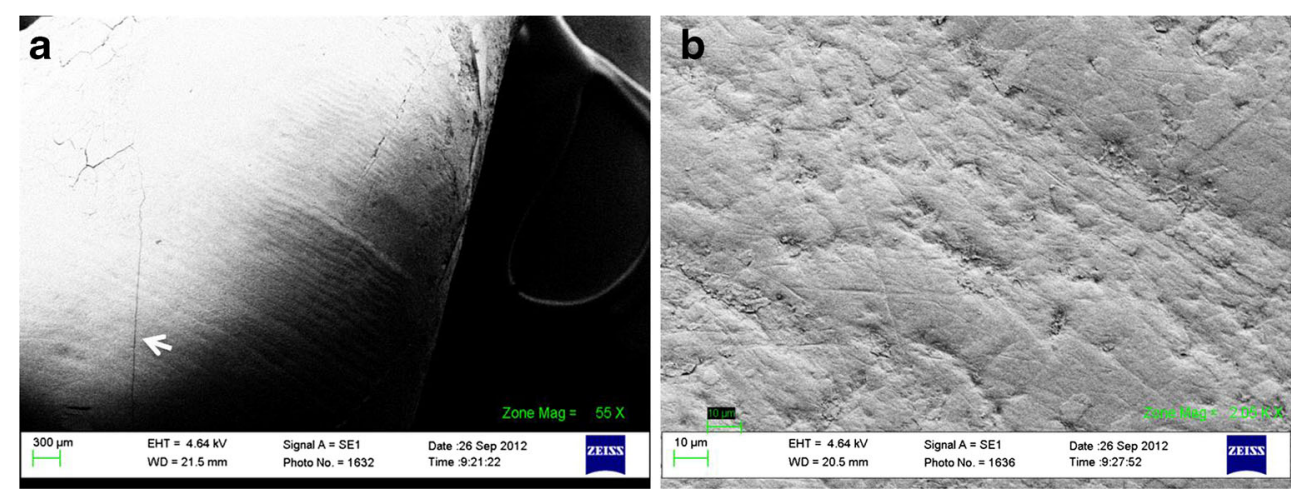

Adhesive remnant index

The ARI scores for the adhesive remaining on the teeth enamel surfaces after debonding are shown in Table 3. Acid etching significantly increased the proportion of specimens in the category ARI $=2-3$; except for the Er:YAG laser group, in which acid etching had no significant effect.

The laser treatment yielded no significant differences in the ARI scores among non acid-etched samples (chi-square= 4.04; $P=0.13$ ). However, when comparing the distribution of ARI scores depending on the laser type in acid-etched specimens, both ultrashort laser and control groups registered a greater proportion of samples in the category $A R I=2-3$ than in the category ARI $=0-1$. The opposite results were observed for the Er:YAG laser group (chi-square $=8.42 ; P=0.015$ ).

\section{SEM observations}

Representative SEM images of debonded enamel surfaces after SBS testing are reported in Figs. 2, 3, 4 and 5.

Figure 2 includes micrographs of enamel surfaces treated with "no laser/no acid". All samples of this subgroup scored " 0 " in the ARI index (Table 3), showing no adhesive residuals remaining on the teeth surfaces (Fig. 2b). The enamel appears intact, although some microcracks can be observed (Fig. 2a). Such cracks may have occurred due to the metalizing traction or to the SEM vacuum.
Figure 3 shows micrographs of teeth surfaces etched with "Er:YAG laser/no acid". In this subset less than $50 \%$ of the adhesive remained on the enamel surface (ARI=1) (Fig. 3a). Sometimes the teeth surfaces contain remarkable peaks and valleys. Although signs of fusion and solidification may be observed, no superficial cracks were identified (Fig. 3b).

Figure 4 displays micrographs of enamel surfaces treated with "ultrashort laser/no acid" after SBS testing. ARI=1 was the most common failure mode. Less than $50 \%$ of the adhesive remained on the teeth surfaces (Fig. 4a). Figure $4 b$ shows a resin-free zone in which an undulated surface produced by ultrashort laser irradiation can be noticed.

Figure 5 comprises micrographs of enamel surfaces etched "with ultrashort laser/acid". More than $50 \%$ of the adhesive remained on the teeth surfaces (Fig. 5a). $\mathrm{ARI}=2$ was the predominant failure mode when acid was applied after ultrashort laser. In this case, the phosphoric acid attenuated the pattern left by ultrashort laser processing, although it is still evident (Fig. 5b). Cracks may have occurred due to the metalizing traction or because of the SEM vacuum.

\section{Discussion}

In vitro measurements of the shear debonding forces have been rated as an acceptable methodology to determine future in vivo comparative conditions [14, 27, 28].
Fig. 3 SEM micrographs $(4.64 \mathrm{kV})$ of a debonded specimen treated with "Er:YAG laser/no acid" $(\mathbf{a} \times 55 ; \mathbf{b} \times 1.97 \mathrm{~K})$
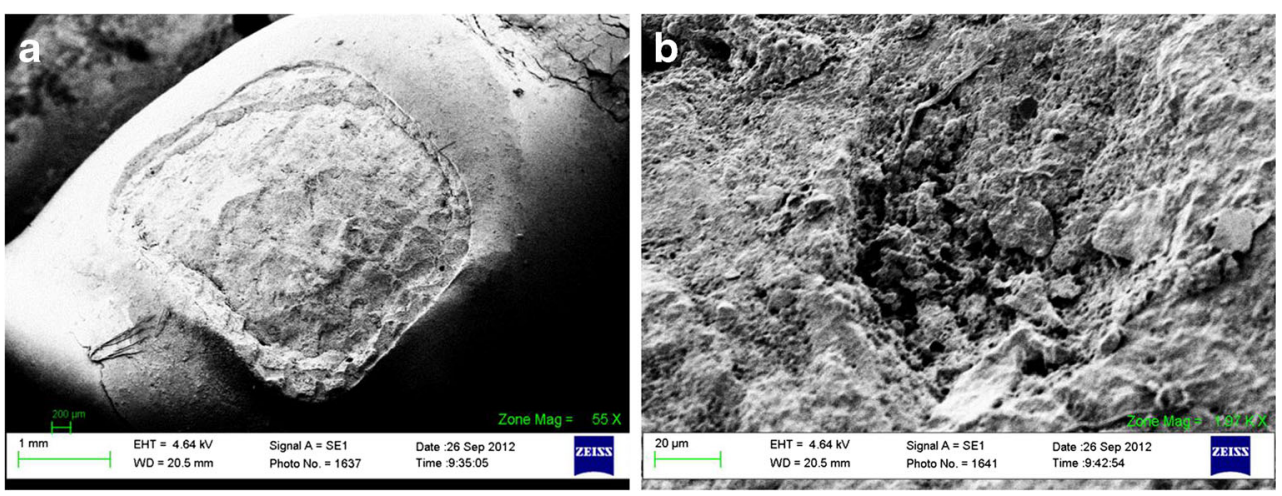
Fig. 4 SEM images $(4.64 \mathrm{kV})$ of a debonded sample treated with "Ti:Sapphire/no acid" $(\mathbf{a} \times 55 ; \mathbf{b} \times 1.97 \mathrm{~K})$
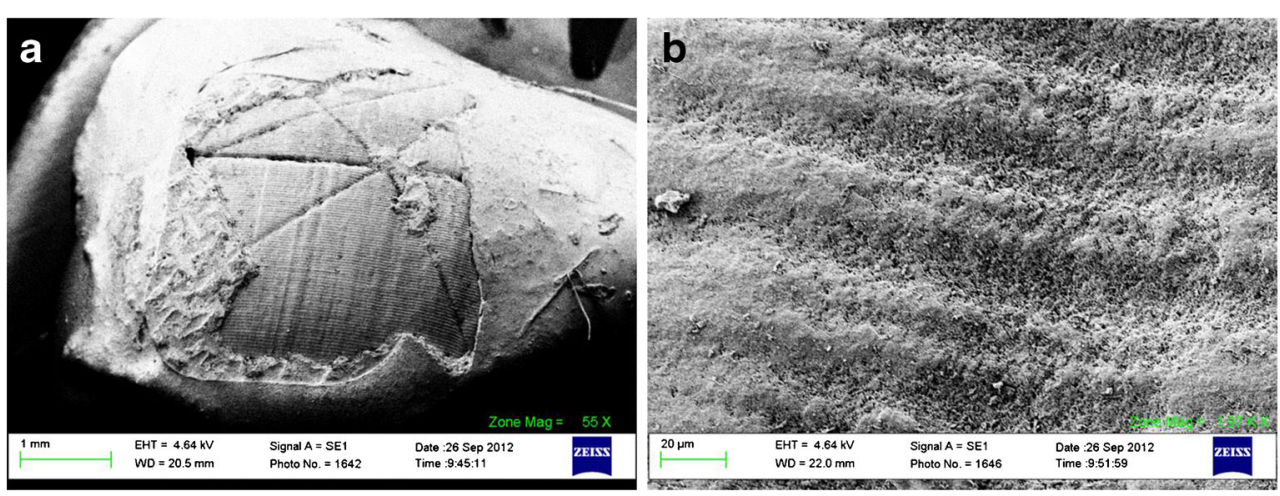

The results of the current experiment require the rejection of the null hypothesis, as differences among the experimental subgroups were confirmed.

When the teeth enamel surfaces were acid-etched, no significant differences were found for different laser treatments (Table 2). Nevertheless, the bond strength at the bracket/enamel interface significantly decreased in the case of teeth surfaces treated with "no laser/no acid" and "Er: YAG laser/no acid" (Table 2). Findings concerning the SBS values before and after acid application in the "no laser" group were consistent with other studies [15, 28-31]. Acid etching generates microporosities on the enamel surfaces through which the luting resin can penetrate [32]. After polymerizing, the micromechanical interlocking of resin tags within the acid-etched enamel surfaces provides the best achievable adhesion [33]. However, the decalcification of the enamel surface caused by acid etching, facilitates the caries attack [4].

The results of this investigation demonstrate that bonding to Er:YAG laser-treated enamel surfaces provide significantly weaker SBS values than bonding to simply acid-etched surfaces. Nonetheless, the combination of Er:YAG laser plus acid etching produced statistically similar SBS to that of acid-etched surfaces non treated with laser. Such results are in good agreement with former studies $[2,13,16]$. Hibst et al. and Altundasar et al. discovered microcracks on teeth enamel surfaces treated with Er:YAG laser that could be interpreted as a sign of thermal damage [20,34]. Authors reporting lower bond strengths in related research argued that microcracks constituted weak regions on the teeth surfaces that give rise to fractures and contaminant filtrations to the tissues $[35,36]$. In contrast, some studies find similar or even greater bracket-to-enamel bond strengths when the Er: YAG laser is applied than when the enamel surfaces are just acid-etched [17, 37-39]. Such contradictory results may be attributed to differences among the study protocols. Previous investigations have demonstrated the influence of water flow rate [40], air pressure [41], pulse duration [42], and laser irradiation distances [14] on the ablation rate, efficiency, surface morphology and SBS values. Hence, with the parameters programmed in our experiment it has been evidenced that Er:YAG laser irradiation of human enamel surfaces is not a good alternative to phosphoric acid etching for bonding brackets.

Therefore, either if samples were not laser processed or Er:YAG laser was used, greater SBS values were recorded when the enamel surfaces were acid-etched afterwards. Conversely, the ultrashort laser performed equally in terms of SBS regardless of the use of acid etching (Table 2). The ultrashort laser ability to provide high SBS values without applying phosphoric acid may be due to the micro and nanoroughness produced by laser ablation, which determines an undulated enamel surface texture (Fig. 4b).

To our knowledge, this is the first study on the adhesion of brackets to enamel that uses an ultrashort pulsed laser as a conditioner. In the current experiment, this type of laser has proved to be an appropriate substitute for orthophosphoric acid or Er:YAG laser. With the ultrashort laser, the practical
Fig. 5 SEM images $(4.64 \mathrm{kV})$ of a debonded specimen treated "Ti:Sapphire/acid" (a $\times 55$; b $\times 1.97 \mathrm{~K}$ )
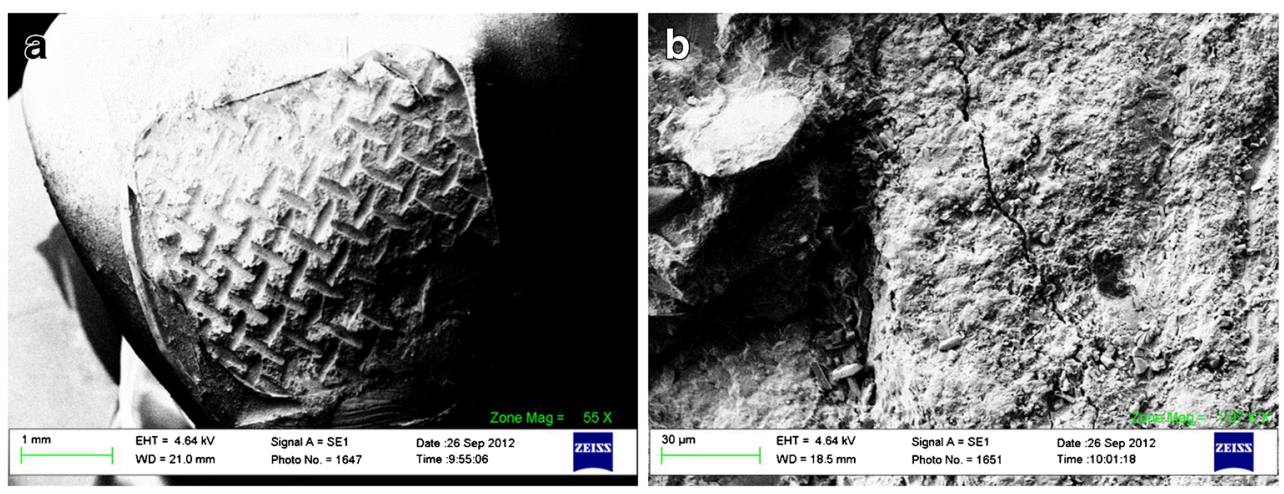
absence of thermal load on the remaining dental tissues prevents the formation of microcracks [23] that could impair the adhesion of brackets to enamel. According to our results, the ultrashort laser might replace the phosphoric acid, equaling the SBS and avoiding the adverse effects of acid etching. With this laser, the induction of microstructural changes on the irradiated enamel is minimal; it does not require irrigation and the acoustic disturbance is minimized [23]. Ultrashort pulses could induce thermal fatigue and mechanical damage of dehydrated enamel and dentin [43]. However, as the ultrashort laser generates a plasma-induced ablation, the thermal damage is always lower than that produced with erbium-based laser systems, which emit longer pulses. In our study, the premolar teeth were always hydrated; thereby the adverse effects that may cause the ultrashort laser on dehydrated enamel surfaces were avoided. Although Fig. $5 \mathrm{~b}$ shows a crack on the enamel surface, which could seem contradictory with the above discussion, this fissure may be due to electron collisions, to the traction generated during metallization or even to the SEM vacuum.

Microscopic observations of the failure sites provided some useful information (Figs. 2, 3, 4, 5). When no acid was applied after the tested laser treatments, more ARI $=0-1$ values were recorded (Table 3 and Figs. 2, 3, 4) probably because the adhesive does not have enough retention into the enamel causing the bracket debonding. In the surfaces treated with "no laser/acid"; and on enamel surfaces treated with "ultrashort laser/acid" (Fig. 5), most samples recorded ARI scores $=2-3$ (Table 3 ). These results are consistent with the literature [14, 15, 28]. Dunn et al. [32] attributed such effect to a blending of the typical pattern of the acid-etched enamel that might prevent the penetration of resin into the enamel surfaces. This can be advantageous for removing the residues after debonding, because less adhesive is expected to be left on the enamel surfaces. However, there is an increased risk of enamel fracture at the time of debonding [28]. When using ultrashort laser, although no differences in SBS were observed between acid-etched and non acidetched samples, the subsequent application of phosphoric acid might possibly increase the depth of the microretentions. This would make the resin tags deeper and more retentive, leaving more adhesive resin layering on the enamel surfaces.

Clinical trials are necessary to support these conclusions, as ideal laboratory conditions are not common in daily practice [44]. Furthermore, the type of adhesive resin and the strict following of the manufacturers' instructions are also key factors for clinical success [45]. Despite the results obtained with ultrashort lasers in these and other in vitro tests, some drawbacks still preclude their implementation for the clinical practice. Among them, the time to etch the enamel surfaces still remains very long as a result of the small etching rate per pulse and the low repetition rates available. However some ultrashort laser systems for microstructuring purposes are being developed and even already commercialized reaching repetition rates in the megahertz range what should overcome the lack of competitivity of this technique. The same can be said with regard to the equipment costs and the dimensions of the laser processing system. In the last years, remarkable steps towards the miniaturization and therefore, the reduction of the investment costs, have been done which foresees a promising future for some applications in the field of odonthology.

\section{Conclusions}

Within the limitations of this study, ultrashort pulsed laser seems to be an optimal alternative for bonding orthodontic brackets to enamel. As the adhesion provided by ultrashort laser irradiation and acid etching is comparable, the adverse effects of phosphoric acid can be avoided by using this laser system.

\section{References}

1. Proffit WR (1986) Contemporary orthodontics. Mosby, Toronto

2. Martínez-Insúa A, Da Silva DL, Rivera FG, Santana-Penín UA (2000) Differences in bonding to acid-etched or Er:YAG-lasertreated enamel and dentin surfaces. J Prosthet Dent 84:280-288

3. Bishara SE, Oonsombat C, Soliman MM, Warren JJ, Laffoon JF, Ajlouni R (2005) Comparison of bonding time and shear bond strength between a conventional and a new integrated bonding system. Angle Orthod 75:237-242

4. Lasmar MF, Reher VG, Lalloo R, Reher P (2012) Enamel demineralization and bracket bond strength when etching with acid and / or Er:YAG laser. Aust Dent J 57:190-195

5. Boyd RL (1994) Comparison of three self-applied topical fluoride preparations for control of decalcification Angle Orthod 64:86

6. Ogaard B, Rølla G, Arends J (1988) Orthodontic appliances and enamel demineralization. Part 1. Lesion development. Am J Orthod Dentofacial Orthop 94:68-73

7. Sognnaes RF, Stern RH (1965) Laser effect on resistance of human dental enamel to demineralization in vitro. JS Calif Dent Assoc 33:328-329

8. Hicks MJ, Flaitz CM, Westerman GH, Berg JH, Blankenau RL, Powell GL (1993) Caries-like lesion initiation and progression in sound enamel following argon laser irradiation: an in vitro study. ASDC J Dent Child 60:201-206

9. Westerman GH, Hicks MJ, Flaitz CM, Blankenau RJ, Powell GL, Berg JH (1994) Argon laser irradiation in root surface caries: in vitro study examines laser's effects. J Am Dent Assoc 125:401407

10. Stratmann U, Schaarschmidt K, Schurenberg M, Ehmer U (1995) The effect of ArF-excimer laser irradiation of the human enamel surface on the bond strength of orthodontic appliances. Scanning Microsc 9:469-476

11. Moritz A, Sperr W, Schoop U, Goharkhay K, Gutknecht N, Doertbudak O (1997) Nd:YAG laser irradiation of infected root canals in combination with microbiological examinations. J Am Dent Assoc 128:1525-1530 
12. Hamamci N, Akkurt A, Başaran G (2010) In vitro evaluation of microleakage under orthodontic brackets using two different laser etching, self etching and acid etching methods. Lasers Med Sci $25: 811-816$

13. Von Fraunhofer JA, Allen DJ, Orbell GM (1993) Laser etching of enamel for direct bonding. Angle Orthod 63:73-76

14. Başaran G, Hamamci N, Akkurt A (2011) Shear bond strength of bonding to enamel with different laser irradiation distances. Lasers Med Sci 26:149-156

15. Lee BS, Hsieh TT, Lee YL, Lan WH, Hsu YJ, Wen PH, Lin CP (2003) Bond strengths of orthodontic bracket after acid-etched, Er: YAG laser-irradiated and combined treatment on enamel surface. Angle Orthod 73:565-570

16. Kim JH, Kwon OW, Kim HI, Kwon YH (2005) Effectiveness of an Er:YAG laser in etching the enamel surface for orthodontic bracket retention. Dent Mater J 24:596-602

17. Hosseini MH, Namvar F, Chalipa J, Saber K, Chiniforush N, Sarmadi S, Mirhashemi AH (2012) Comparison of shear bond strength of orthodontic brackets bonded to enamel prepared by Er:YAG laser and conventional acid-etching. J Dent (Tehran) 9:20-26

18. Li ZZ, Reinisch L, Van de Merwe WP (1992) Bone ablation with Er:YAG and $\mathrm{CO}_{2}$ laser: study of thermal and acoustic effects. Lasers Surg Med 12:79-85

19. Hibst R (2004) Laser for caries removal and cavity preparation: state of the art and future directions. J Oral Laser Appl 2:203-212

20. Hibst R, Keller U (1989) Experimental studies of the application of the Er:YAG laser on dental hard substances: I. Measurement of the ablation rate. Lasers Surg Med 9:338-344

21. Strickland D, Mourou G (1985) Compression of amplified chirped optical pulses. Opt Commun 56:219-221

22. Chichkov BN, Momma C, Nolte S, von Alvensleben F, Tünnermann A (1996) Femtosecond, picosecond and nanosecond laser ablation of solids. Appl Phys A 63:109-115

23. Luengo MC, Portillo M, Sánchez JM, Peix M, Moreno P, García A, Montero J, Albaladejo A (2013) Evaluation of micromorphological changes in tooth enamel after mechanical and ultrafast laser preparation of surface cavities. Lasers Med Sci 28:267-273

24. Kohns P, Zhou P, Störmann R (1997) Effective laser ablation of enamel and dentine without thermal side effects. J Laser Appl 9:171-174

25. Portillo Muñoz M, Lorenzo Luengo MC, Sánchez Llorente JM, Peix Sánchez M, Albaladejo A, García A, Moreno Pedraz P (2012) Morphological alterations in dentine after mechanical treatment and ultrashort pulse laser irradiation. Lasers Med Sci 27:53-58

26. Serbin J, Bauer T, Fallnich C, Kasenbacher A, Arnold WH (2002) Femtosecond lasers as novel tool in dental surgery. Appl Surf Sci 197-198:737-740

27. Goracci C, Margvelashvili M, Giovannetti A, Vichi A, Ferrari M (2012) Shear bond strength of orthodontic brackets bonded with a new self-adhering flowable resin composite. Clin Oral Investig. doi:10.1007/s00784-012-0729-x

28. Gokcelik A, Ozel Y, Ozel E, Arhun N, Attar N, Firatli S, Firatli E (2007) The influence of Er:YAG laser conditioning versus selfetching adhesives with acid etching on the shear bond strength of orthodontic brackets. Photomed Laser Surg 25:508-512

29. Attrill DC, Farrar SR, King TA, Dickinson MR, Davies RM (2000) Er:YAG $(\lambda=2.94 \mu \mathrm{m})$ laser etching of dental enamel as an alternative to acid etching. Lasers Med Sci 15:154-161
30. Obeidi A, Liu PR, Ramp LC, Beck P, Gutknecht N (2010) Acidetch interval and shear bond strength of Er, Cr:YSGG laserprepared enamel and dentin. Lasers Med Sci 25:363-369

31. Lima AF, da Silva VB, Soares GP, Marchi GM, Baggio Aguiar FH, Lovadino JR (2012) Influence of previous acid etching on interface morphology and bond strength of self-etching adhesive to cavosurface enamel. Eur J Dent 6:56-62

32. Dunn WJ, Davis JT, Bush AC (2005) Shear bond strength and SEM evaluation of composite bonded to Er:YAG laser-prepared dentin and enamel. Dent Mater 21:616-624

33. Van Meerbeek B, De Munck J, Mattar D, Van Landuyt K, Lambrechts P (2003) Microtensile bond strengths of an etch\&rinse and self-etch adhesive to enamel and dentin as a function of surface treatment. Oper Dent 28:647-660

34. Altundasar E, Ozçelik B, Cehreli ZC, Matsumoto K (2006) Ultramorphological and histochemical changes after ER, CR:YSGG laser irradiation and two different irrigation regimes. J Endod 32:465-468

35. De Munck J, van Meerbeek B, Yudhira R, Lambrechts P, Vanherle G (2002) Micro-tensile bond strength of two adhesives to Erbium: YAG-lased vs. bur-cut enamel and dentin. Eur J Oral Sci 110:322329

36. Obeidi A, McCracken MS, Liu PR, Litaker MS, Beck P, Rahemtulla F (2009) Enhancement of bonding to enamel and dentin prepared by Er, Cr:YSGG laser. Lasers Surg Med 41:454- 462

37. Liberman R, Segal TH, Nordenberg D, Serebro LI (1984) Adhesion of composite materials to enamel: comparison between the use of acid and lasing as pretreatment. Lasers Surg Med 4:323327

38. Başaran G, Ozer T, Berk N, Hamamci O (2007) Etching enamel for orthodontics with an erbium, chromium:yttrium-scandiumgallium-garnet laser system. Angle Orthod 77:117-123

39. Özer T, Başaran G, Berk N (2008) Laser etching of enamel for orthodontic bonding. Am J Orthod Dentofacial Orthop 134:193197

40. Mir M, Meister J, Franzen R, Sabounchi SS, Lampert F, Gutknecht $N$ (2008) Influence of water-layer thickness on Er:YAG laser ablation of enamel of bovine anterior teeth. Lasers Med Sci 23:451-457

41. Rizcalla N, Bader C, Bortolotto T, Krejci I (2012) Improving the efficiency of an Er:YAG laser on enamel and dentin. Quintessence Int 43:153-160

42. Li ZZ, Code JE, Van De Merwe WP (1992) Er:YAG laser ablation of enamel and dentin of human teeth: determination of ablation rates at various fluences and pulse repetition rates. Lasers Surg Med 12:625-630

43. Rego-Filho FD, Dutra-Corrêa M, Nicolodelli G, Bagnato VS, de Araujo MT (2013) Influence of the hydration state on the ultrashort laser ablation of dental hard tissues. Lasers Med Sci 28:215-222

44. Oyagüe RC, Monticelli F, Toledano M, Osorio E, Ferrari M, Osorio R (2009) Effect of water aging on microtensile bonds strength of dual-cured resin cements to pre-treated sintered zirconium-oxide ceramics. Dent Mater 25:392-399

45. Gomes AL, Castillo-Oyagüe R, Lynch CD, Montero J, Albaladejo A (2013) Influence of sandblasting granulometry and resin cement composition on microtensile bond strength to zirconia ceramic for dental prosthetic frameworks. J Dent 41(1):31-41 